\title{
Frontalis Sling Suspension Surgery for Aquired Myogenic Ptosis
}

\author{
Balaji Kannan MBBS, DO, DNB*
}

Assistant Professor, Department of Ophthalmology, Dhanalakshmi Srinivasan Medical College, Perambalur, Tamilnadu, India

DOI: $10.36347 /$ sasjs.2021.v07i02.006

| Received: 22.01.2021 | Accepted: 08.02.2021 | Published: 10.02 .2021

*Corresponding author: Balaji Kannan MBBS, DO, DNB

Abstract

Original Research Article

Correction of acquired myogenic ptosis with poor levator function by frontalis muscle suspension is the gold standard. It creates a linkage between the frontalis muscle and the tarsal plate of upper eyelid. Various different materials have been used for frontalis suspension, in particular silicon rod is an effective and safe material used in treating ptosis with poor levator function [6]. The elasticity and ease of adjustment of silicon rod are ideal characteristics for suspension material used to treat acquired myogenic ptosis with poor levator function. We report our experience with silicone rod (Aurosling from Aurolab limited, India) for frontalis sling suspension surgery for acquired myogenic ptosis with poor levator function.

Keywords: Frontalis, Sling Suspension, Aquired, Myogenic.

Copyright $\odot 2021$ The Author(s): This is an open-access article distributed under the terms of the Creative Commons Attribution 4.0 International License (CC BY-NC 4.0) which permits unrestricted use, distribution, and reproduction in any medium for non-commercial use provided the original author and source are credited.

\section{Materials ANd Methods}

26 lids of 19 consecutive patients meeting the inclusion criteria were enrolled for the study. The inclusion criteria were severe acquired ptosis with poor levator function i.e. upper lid margin and pupillary reflex distance (MRD 10 of 0 to $1 \mathrm{~mm}$ and poor levator function $<4 \mathrm{~mm}$ (Burke's method), Third nerve palsy, Chronic progressive external ophthalmoplegia (CPEO), Myasthenic gravis (MG), Post traumatic levator disinsertion, Myotonic dystrophy and Congenital fibrosis syndrome.

Exclusion criteria were acquired ptosis e.g. Horner's syndrome, Blepharochalasis, Dermatochalasis, Mechanical ptosis, Mild or Moderate congenital ptosis (MRD 1>1). The surgery was performed under local anesthesia in adults and general anesthesia in children. Frontalis sling suspension was performed using modified Fox pentagon technique using Aurosling (silicone rod frontalis suspension set). Five incision sites for Fox pentagon were marked. First two marks were made in upper lid lateral to temporal limbus and medial to medial limbus $2 \mathrm{~mm}$ above lash line. Next two marks were made just medial and lateral to lid incision above superior brow hairs. A forehead incision was then marked midway above $1 \mathrm{~cm}$ above brow. The five incisions were then made with Ellman RF cautery. A pocket was dissected beneath frontalis muscle superiorly for burying the sleeve. The needle of sling suspension set was then slightly bent and passed from central forehead incision to lid incision and back to forehead incision in clockwise manner to form a pentagon. Lid Guard was used to protect the cornea and support the lid. The two needles were then passed through the sleeve and the sling was tightened to obtain required lid height and contour. The silicone rod was then cut and the sleeve was buried in pocket made between frontalis muscle. The forehead incision was then closed with 6-0 vicryl suture. Frost suture was then taken and left in place for one day. Post operatively lid height, contour, lagophthalmos and corneal exposure was assessed in all the patients.

In case of a bilateral frontalis sling surgery ideal upper lid height postoperatively is $1 / 2 \mathrm{~mm}$ below superior limbus. But in case of a unilateral surgery it needs to be matched with the lid height of the other eye. Under correction is desirable in cases having poor Bells phenomenon such CPEO, MG \&Third nerve palsy. The post-operative correction was graded as good if the lid height was equal to or $1 \mathrm{~mm}$ lower than the desired correction, fair if it was 1 to $2 \mathrm{~mm}$ lower than the desired level and poor if it was more than $2 \mathrm{~mm}$ lower than the desired level. Intraoperative and postoperative complications were recorded. The patients were followed up postoperatively for a minimum period of six months.

\section{RESULTS}

The age of patients ranged from 9 years to 66 years.39 patients were male and 22 patients were 
female. The pre-operative diagnosis were Ocular myasthenia $9(47 \%)$ cases, CPEO $5(26 \%)$ cases, Third cranial nerve palsy $2(10 \%)$ cases, each one case Post traumatic LPS disinsertion, Myotonic dystrophy, Congenital ocular fibrosis syndrome (5\%).

Pre operatively 7 patients had poor Bells phenomenon. Surgical procedure performed was frontalis sling suspension in 15 patients, YV plasty and Frontalis sling in 3 patients and Levator disinsertion and Frontalis sling in 1 patient.

Postoperative $19(72.07 \%)$ eyes had good correction. $6(23.07 \%)$ eyes had fair correction and 1 (3\%) eye with poor correction.
Lagophthalmos was grading 1 in 4 (15\%) eyes, grade $2 \&$ grade 3 in one eye $(3 \%)$ respectively.

Complications encountered were corneal exposure in 2 patients; they were managed by use of topical lubricants and taping at night, along with loosening of sling.

One patient developed pre septal cellulitis and was managed on parenteral antibiotics and removal of sling. One patient had granuloma formation which was managed conservatively.

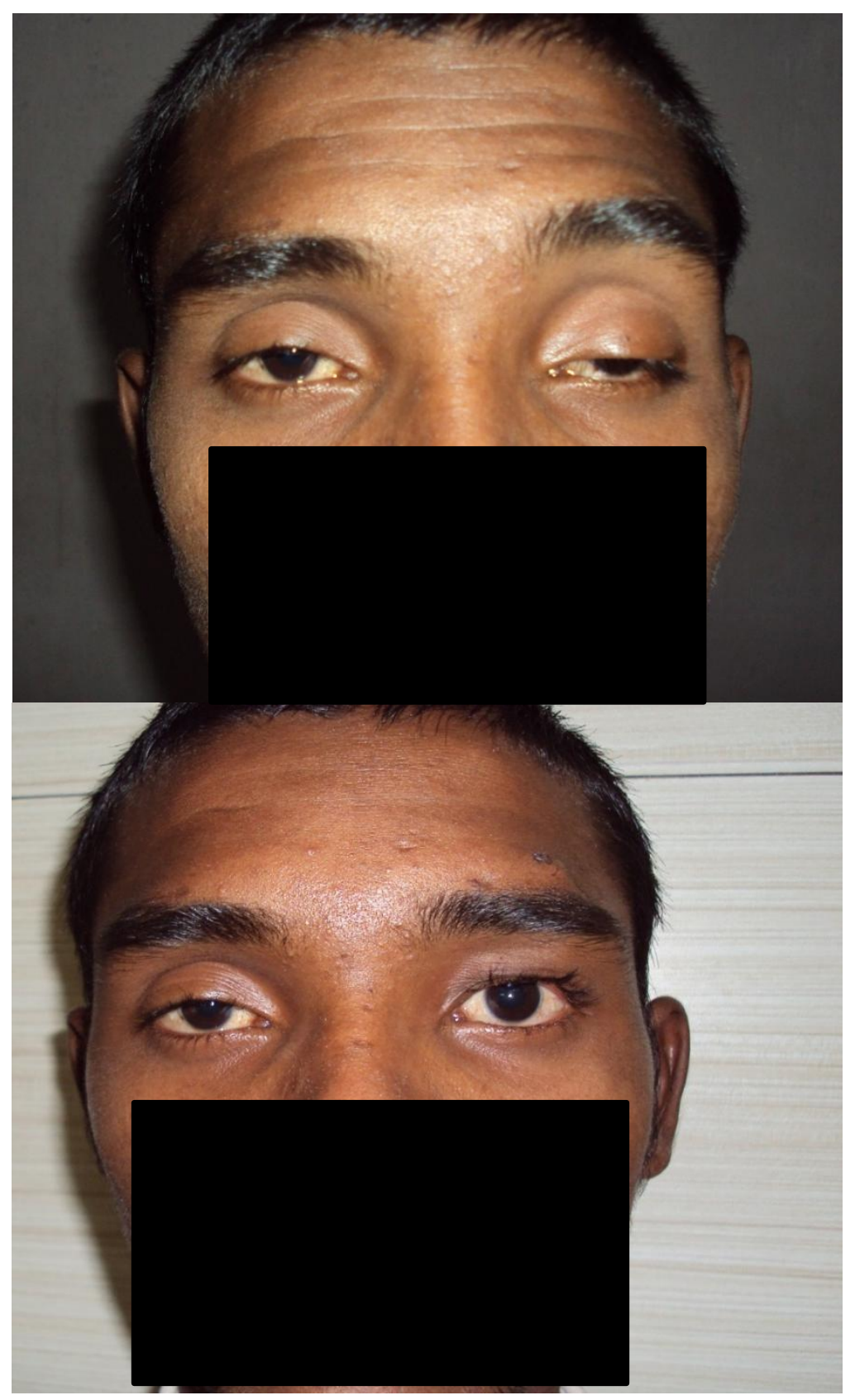




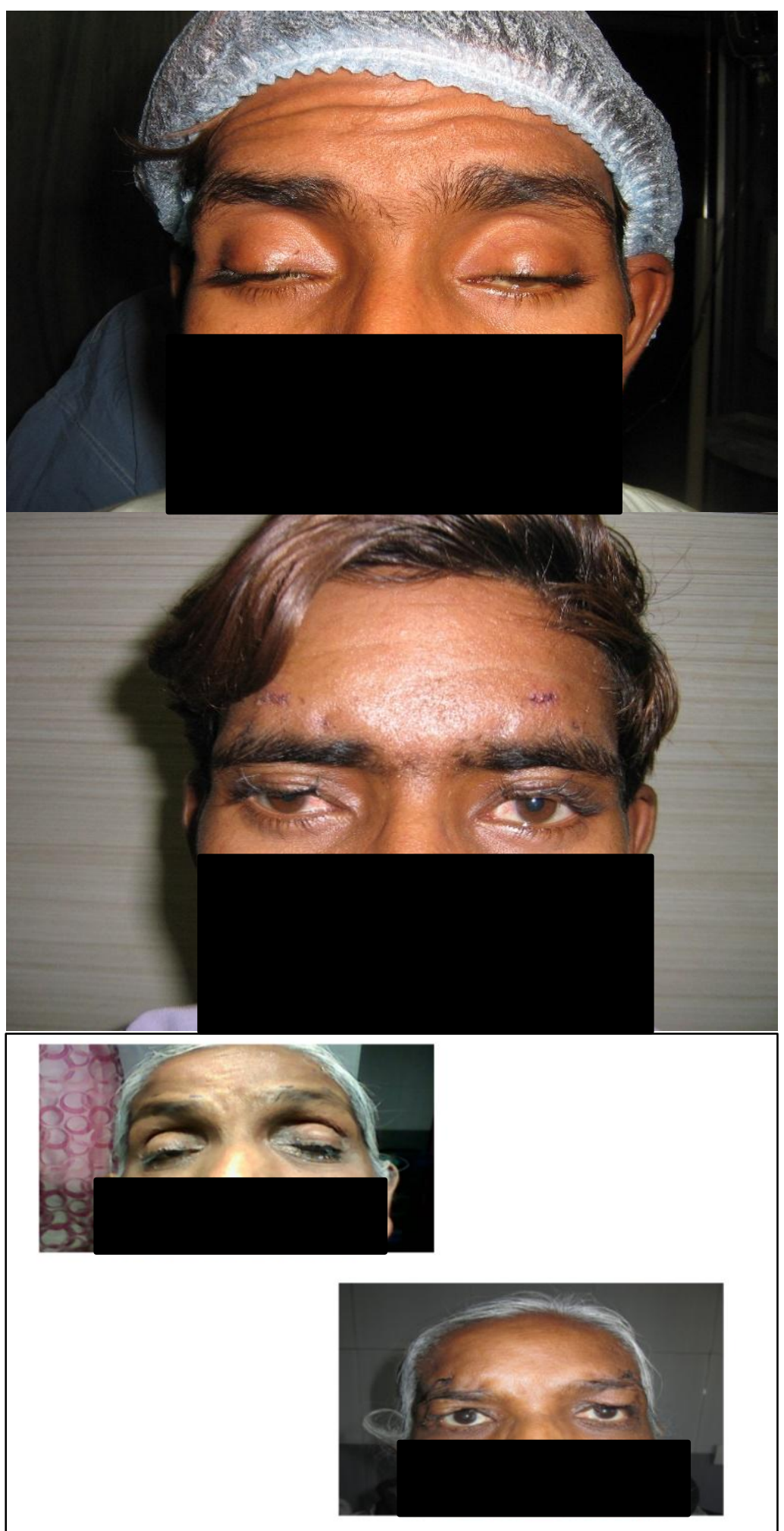

\section{DISCUSSISON}

Ever since 1966 when Tillet et al. [1] reported use of Silicone band no. 40 for frontalis sling suspension surgery the material has been found to have excellent biocompatibility. Various different types of silicone rods and bands along with different surgical techniques have been used and reported but all of them in a small number of patients. There are no published reports for Indian population. Our series presents the results of frontalis sling suspension using silicone rod material in Indian population.

\section{Silicone rod $[2,3]$ as a material has}

1. Excellent Biocompatibility that is well tolerated by body tissues

2. It has good elasticity, which provides for good lid closure.

3. It can be easily adjusted because of use of sleeve. 
The severity of ptosis may be of variable progression in some conditions such as CPEO, MG and Myopathy and it may increase with worsening of myopathy or may improve as in cases of myasthenia gravis [4, 5]. All these conditions may need sling adjustment, which is easily done in case of a silicone sling surgery.

\section{REFERENCES}

1. Tillet CW, Tillet GM. Silicone sling in the correction of ptosis. Am J Opthalmol 1966;62(3):521-3

2. Leone CR Jr, Rylander G. A modified silicone frontalis sling for the correction of blepharoptosis. Am J Ophthalmol 1978:85:802-5.
3. Carter SR, Meecham WJ, Seiff SR. Silicone frontalis slings for the correction of blepharoptosis: indications and efficacy. Ophthalmology. 1996; 103:623-30.

4. Green JP, Wojno T. Removal of an infected silicone rod frontalis sling without recurrence of ptosis. Ophthal Plast Reconst Surg. 1997; 13:285-6.

5. Bernardini FP, De Conciliis C, Devoto MH. Frontalis suspension sling using a silicone rod in patients affected by myogenic blepahroptosis. Orbit. 2002; 21:195-8.

6. Ben Simon GJ, Macedo AA, Schwarcz RM, Wang DY, McCann JD, Goldberg RA. Frontalis suspension for upper eyelid ptosis: evaluation of different surgical designs and suture material. Am J Ophthalmol. 2005:140:877-85. 